\title{
Contribution of Tocols to Food Sensorial Properties, Stability, and Overall Quality
}

\author{
Amélia Delgado (D), ${ }^{1}$ Said Al-Hamimi ${ }^{1},{ }^{2}$ Mohamed Fawzy Ramadan (iD, ${ }^{3}$ \\ Maryna De Wit $\mathbb{D}^{4},{ }^{4}$ Alessandra Durazzo $\mathbb{D}^{5},{ }^{5}$ Kar Lin Nyam $\mathbb{D}^{6},{ }^{6}$ and Manel Issaoui $\mathbb{D}^{7}$ \\ ${ }^{1}$ MED-Mediterranean Institute for Agriculture, Environment and Development, University of Algarve, Gambelas Campus, \\ Faro 8005-191, Portugal \\ ${ }^{2}$ OQ, SablaX, P.O. Box 261, Muscat 118, Oman \\ ${ }^{3}$ Deanship of Scientific Research, Umm Al-Qura University, Makkah, Saudi Arabia \\ ${ }^{4}$ Department of Microbial, Biochemical and Food Biotechnology, University of the Free State, Nelson Mandela Road 205, \\ P.O. Box 339, Bloemfontein, Free State, South Africa \\ ${ }^{5}$ CREA-Research Centre for Food and Nutrition, Rome, Italy \\ ${ }^{6}$ UCSI University, Kuala Lumpur, Malaysia \\ ${ }^{7}$ Lab-NAFS 'Nutrition-Functional Food \& Vascular Health', Faculty of Medicine, University of Monastir, Monastir 5019, Tunisia \\ Correspondence should be addressed to Amélia Delgado; amdelgado@ualg.pt
}

Received 21 August 2020; Revised 7 October 2020; Accepted 19 November 2020; Published 3 December 2020

Academic Editor: Antoni Szumny

Copyright @ 2020 Amélia Delgado et al. This is an open access article distributed under the Creative Commons Attribution License, which permits unrestricted use, distribution, and reproduction in any medium, provided the original work is properly cited.

\begin{abstract}
This paper reviews the contribution of tocopherols and tocotrienols (tocols) to food quality as well as their bioactivity and healthpromoting properties, which have attracted researchers and food technologists. Tocols are lipophilic phenolic antioxidants encompassing tocopherols that are characterized by a saturated side chain and tocotrienols with an unsaturated isoprenoid side chain. Tocols are natural constituents of several foods like dairy, vegetable oils, nuts, and grains. Their presence in foods, namely, as food additives, helps prevent lipid oxidation, which negatively affects the sensorial quality of foods, and even the nutritional value and safety. Supplementation of animals' diets with tocopherols has proven its effectiveness in preserving fresh color and flavor of the meat. Although alfa-tocopherol displays much higher vitamin E activity than other tocols, health outcomes have been reported for tocotrienols, thus calling for more studies.
\end{abstract}

\section{Introduction}

The interest in the study of tocols has dramatically increased in the last decades, most probably in raising awareness on the health impact of individual food items and diets. Tocols include tocopherols and tocotrienols, whose biosynthetic pathways are exclusive of photosynthetic organisms (plants and cyanobacteria) and are essential nutrients in mammals mostly due to their vitamin E activity and/or antioxidant and other bioactivities [1]. Tocols are lipophilic phenolic antioxidants that protect polyunsaturated fatty acids (PUFA) from lipid peroxidation in food matrices and in the human body, where reactive oxygen species (ROS) may come from environmental exposure or are formed as side products of cell metabolism. Tocols and other antioxidants accept unshared highly energetic electrons from ROS, thus preventing damage to unsaturated fatty acids, whether part of a food or biological membrane.

The primary dietary sources of tocols are lipids, notably butter and vegetable oils (as virgin olive oil). The current review encompasses a rapid overview of tocols' chemistry, their main features, and occurrence in foods, a brief review on sensorial assessment, and other factors that determine food choice. We also describe the contribution of main tocols to color and flavor of foods, as well as their role in sensorial food quality. We aim to reach students and researchers in food quality and nutrition and food technologists, in search of focused information to support their research and innovations efforts. 


\section{Sensorial Perceptions and Food Choices}

Humans associate wider roles and significance to food, mainly surpassing its primary function of supplying essential nutrients. Food is associated with pleasure, social and religious occasions, and, more recently, healthy and sustainable lifestyles. A myriad of diets and processed foods have been arising to the market, advertised as healthy and/or environmentally friendly, often by blaming or amplifying certain features or constituents of foods to align them with consumers' preferences at the time of shopping [2]. International organizations have been raising attention to climate change and environmental issues, such as soil degradation and biodiversity loss, and the burden of obesity and noncommunicable diseases associated with the so-called “western diet" $[3,4]$.

Combining the constraints related to human health and environmental dimensions while appealing to the senses seems to be a complicated equation in a diet. A very few dietary patterns, notably the Mediterranean Diet (MD), can simultaneously address all these factors, translated in the "one health" approach $[5,6]$. The MD can stimulate the senses through a wide range of colors, flavors, aromas, and scents, which are mainly conveyed by the large quantities and variety of plant-based foods, thus valuing agrobiodiversity and addressing other sustainability factors. In the $\mathrm{MD}$, the food components that bring nutritional, health, and environmental benefits are the same ones that convey colors and flavors [7-9].

When appreciating food, all senses are involved, and our preferences are also dictated by memories, beliefs, cultural aspects, and other subjective factors. In respect to sensorial aspects, the taste of foods is detected by receptors on the tongue and interpreted in the brain. Basic tastes are categorized into sweet (e.g., fig), bitter (e.g., coffee), sour (e.g., yogurt), salty (e.g., table olive), and umami (cheese). Aroma detected by olfactory pathways is usually interlinked with taste, playing an essential role in the sensations caused by a food. The physical sensations (color, temperature, texture, and hardness) and chemical sensations (chemical irritation in the mouth and throat) also affect the overall perception of food [10].

The term "flavor," as used by sensory analysis specialists, refers to all these sensations. When a piece of food is introduced into the mouth, it is smelled in the process and sensed through the gut, and a whole cascade of chemical reactions and nerve responses are triggered. When interpreted in the brain, other factors such as perceptions from the surrounding environment to cultural and ethical judgments are all considered. Thus, the feeling of how enjoyable a meal is or how and when we like or dislike a particular food is highly subjective, variable, and quite complex $[11,12]$.

When examining foods at the molecular level, plant foods stand out for their pigments, like carotenoids, tocols, xanthophylls, chlorophylls, and polyphenols that, besides the color, also act as vitamins, provitamins, or antioxidants; plant foods also contain molecules that convey aroma (e.g., tocols, aldehydes, and aliphatic and triterpenic alcohols) which are often bioactive too, displaying multiple features of interest in foods (color, flavor, and bioactivity) [13].

\section{Tocols and Vitamin E Activity}

The molecular structure of tocopherols consists of a chromanol ring connected to a long carbon side chain. Variations in the number and position of the methyl groups on the ring result in different forms named $\alpha-, \beta-, \gamma^{-}$, and $\delta$-tocopherol, all provided as a blend in the abovementioned dietary sources, although in different proportions and depending on the species and the considered edible part. Tocopherols are more abundant than tocotrienols, which are only found in some plant species' fruits and seeds $[1,14]$.

It has been argued that $\alpha$-, $\beta$-, $\gamma^{-}$, and $\delta$-tocopherols are all forms of vitamin $\mathrm{E}$ with different levels of activity and bioavailability. $\alpha$-Tocopherol is the preferred form of vitamin E, absorbed and accumulated in humans and other mammals. On the other hand, $\beta$-, $\gamma$-, and $\delta$-tocopherols are referred to as having little vitamin $\mathrm{E}$ activity, but they retain similar antioxidant activity and may convey additional health benefits [14-16].

There has been some debate in relation to vitamin activity of tocols. Some authors claim that the 8 isomeric forms of tocopherols and tocotrienols all have vitamin E activity, though to a different extent [1, 17-19], while the EFSA NDA Panel [20] considers vitamin E as being $\alpha$-tocopherol only, despite acknowledging that other tocopherol isomers and tocotrienols may have antioxidant activity. On its turn, NIH [21] accepts that vitamin E may exist in 8 different chemical forms but states that $\alpha$-tocopherol is the only form maintained in plasma and recognized to meet human requirements for vitamin $\mathrm{E}$.

\section{Colors and Flavors of Main Tocols}

Tocopherols and tocotrienols are naturally transparent and viscous substances with colors ranging from light yellow to reddish-brown [14]. When in the form of powders, tocopherols take a tan or tan-to-reddish color. Besides the beneficial health properties, tocols play a vital role in the stability of color and flavor of foods.

Carotenoids and tocopherols are closely related in their functions and location in plants, as both are lipid-soluble antioxidants found in chloroplasts. In addition to their roles in photosynthesis, carotenoids and tocols are essential components of animal diets, including humans, for their vitamin and antioxidant activities [16]. Synergy and reactions between tocopherols, carotenoids, ascorbic acid, and other components have been reported to affect food quality [16].

For instance, the autoxidation of lipids observed in vegetable oils is initiated by the free radicals, leading to the formation of lipid peroxy radicals and finally lipid hydroperoxides, which are unstable and can trigger further propagation reactions. As such compounds play a crucial role as intermediates of oils' autoxidation reactions, the "peroxide value" is a parameter that gives a measure of the extent of primary oxidation of edible oils and is of capital 
importance in their grading and hence in their quality [22]. Propagation reactions triggered by hydroperoxides are known as branching steps or secondary decomposition reactions, and their products are responsible for causing rancid off-flavors. Oxidation of lipids is a major cause of deterioration of the quality of foods affecting flavor, color, texture, and even the nutritional value and safety. Safety is of particular concern when speaking of ultra-processed and frying foods, in which further degradation reactions may occur with the formation of toxic compounds $[23,24]$.

Tocopherols and tocotrienols are best known for their ability to accept high energy electrons (free radicals) and terminate oxidation chain reactions, thus preventing changes in color and flavor of foods containing natural (e.g., hazelnut) or added tocols (e.g., margarine).

Supplementation of feed with tocopherols (in poultry, cattle, and fish diets) has shown effective results in delaying lipid oxidation and subsequently increasing the shelf life with preserved freshly color and flavor. Researches on feed quality and the relation to food quality started in the 1970s and are still a field of interest. The detailed information on the use of tocols in the feed (as vitamin supplements or as preservatives) was reported.

\section{The Role of Tocols in Food Quality}

\subsection{Tocols as Natural Constituents in Food. As lipophilic} molecules, tocols are natural constituents of a range of foods, as dairy (e.g., butter), vegetable oils (as virgin olive oil), nuts (as almonds and hazelnuts), vegetables, and grains (notably wheat germ), which are known sources of vitamin $\mathrm{E}$ and other lipophilic vitamins, as the presence of fat is required for active absorption [20,21]. In addition to the activities referred to above as an antioxidant, vitamin $\mathrm{E}$ is involved in immune function, anti-inflammatory processes, inhibition of platelet aggregation, cell signaling, regulation of gene expression, and other metabolic processes [20,21].

According to EFSA [20], the average $\alpha$-tocopherol absorption from a usual diet is about $75 \%$ and defines adequate intakes for $\alpha$-tocopherol (based on observed intakes in healthy populations) in $13 \mathrm{mg} /$ day for men, $11 \mathrm{mg} /$ day for women, and $9 \mathrm{mg} /$ day for children of both sexes, aged 3 to $<10$ years, and $6 \mathrm{mg} /$ day if aged $<3$ years, considering that no vitamin E deficiencies have been reported in Europe. NIH [21] sets higher levels for the American population, with recommended dietary allowance for $\alpha$-tocopherol of $15 \mathrm{mg} /$ day for adults irrespective of sex and $11 \mathrm{mg} /$ day for children aged 9 to $<13$ and decreasing until $6 \mathrm{mg} /$ day for children aged $<3$ years [25].

The bioavailability of vitamin $\mathrm{E}$ is influenced by a range of factors, including fixed ones, like gender, age, and genetic constitution, as well as others that depend on the environment and can be changed, as food habits and lifestyle, impacting dietary guidelines for different population groups.

Vitamin $\mathrm{E}$ deficiencies are rare and reported in premature babies of very low birth weight, rare inherited disorders, Crohn's disease, cystic fibrosis, or medical conditions interfering with the ability to secrete bile from the liver into the digestive tract [21]. Thus, vitamin E supplements are justifiable only in some instances as, in general, a balanced diet provides the necessary levels of vitamin $\mathrm{E}$ and other tocols for health benefits. It should also be noted that naturally occurring $\alpha$-tocopherol exists in only one stereoisomeric form, known as RRR $\alpha$-tocopherol. In contrast, synthetically produced forms contain equal amounts of all stereoisomers and are known as all-racemic $\alpha$-tocopherol, with about half the potency of the natural form $[21,26]$.

In the body, tocols undergo a series of complex metabolic processes comprising intestinal absorption, vascular transport to the liver, and hepatic sorting by intracellular binding proteins, such as the significant $\alpha$-tocopheroltransfer protein $(\alpha$-TTP), which preferentially binds $\alpha$-tocopherol rather than other tocopherols or tocotrienols $[20,27]$. According to EFSA panel on dietetic products, nutrition, and allergies (NDA) [20], because $\alpha$-TTP and $\omega$-hydroxylase (a key enzyme in the liver) have a much higher affinity towards $\alpha$-tocopherol than other tocopherols, the former one predominantly accumulates in body tissues. In contrast, other tocols are preferentially catabolized in the liver. However, doubt persists on the functions and health outcomes of other tocols, namely, tocotrienols, which have not been so thoroughly studied, and some authors discuss their probable hypocholesterolemic, anticancer, and neuroprotective properties, as well as tocotrienols' potential action against inflammation-associated diseases $[17,19]$.

In the case of ingested natural vitamin E, it is necessary to take into account the interactions with the food matrix, resulting in enhanced bioactivities when synergies are established with other food constituents, such as vitamin $\mathrm{K}$ [27], ascorbic acid, and carotenoids [28].

In this context, the vitamin content of plant foods, and hence nutritional quality, varies widely with a range of factors, including agronomic techniques. Due to the lack of robust data, debate exists on the existence of sufficient differences in sensorial and nutritional quality of organic produce vs. intensive systems [29-31]. When considering the nutritional quality of foods, it is necessary to recognize that competing nutrients can reduce the bioavailability of certain compounds as tocopherols in the food matrix [27]. There is not enough science-based evidence supporting the superior composition on bioactive compounds of organic produce, even though evidence shows that organic foods are lower in toxic compounds bringing proven benefits to human health and the environment. A more in-depth discussion is out of the scope of the present review. For sensorial and nutritional quality, the food matrix seems to have a much higher impact, potentiating synergies between distinct classes of compounds (e.g., tocols and other antioxidants), or reactions with antinutrients that decrease the bioavailability of vitamins and others [32].

The content in vitamin $\mathrm{E}$ of primary dietary sources is given in Table 1, which indicates available data on the composition in other tocols. As deduced from Table 1 and corroborated by authorities [20,21], a balanced diet should provide the necessary amounts of vitamin $\mathrm{E}$ and other potentially health-promoting tocols. As shown in Table 1, the primary natural sources of vitamin $\mathrm{E}$ to the diet are edible oils (notably olive oil) and certain nuts. 
TABle 1: Natural dietary sources of vitamin E and average content (mg/100 mg) according to ANSES-Ciqual food composition table.

\begin{tabular}{lcc}
\hline Food group & Description & Average concentration of $\alpha$-tocopherol (mg/100 g) \\
\hline \multirow{2}{*}{ Dairy } & Butter (80\% fat) & 2.11 \\
& Cheddar cheese (cow's milk) & 0.78 \\
\hline \multirow{2}{*}{ Vegetable oils } & Olive oil (virgin) & 22.3 \\
& Palm oil & 15.9 \\
Grains & Sunflower oil & 57.3 \\
\hline \multirow{2}{*}{ Vegetables } & Wheat germ & 10.2 \\
& Spinach, boiled & 3.98 \\
\hline \multirow{2}{*}{ Fruits } & Basil, fresh & 0.8 \\
& Tomato, raw & 0.66 \\
\hline \multirow{2}{*}{ Nuts } & Mango, pulp, raw & 2.05 \\
& Avocado, pulp, raw & 2.23 \\
& Kiwi & 0.96 \\
\end{tabular}

${ }^{*}$ Commercial oils that may include additional vitamin E as a food additive. Data retrieved from ANSES-Ciqual food composition table: https://ciqual.anses.fr.

Despite the differences of natural and synthetic compounds (including esterification to prolong its shelf life while protecting its antioxidant properties), the organism absorbs and metabolizes different isomers and esters as efficiently as natural molecules [21].

5.2. Tocols as Food Additives. The Joint FAO/WHO Expert Committee on Food Additives (JECFA) defines food additives as "substances added to food to maintain or improve its safety, freshness, taste, texture, or appearance" [33]. The safety of additives that can be used in foods traded internationally should be evaluated firstly by the joint FAO/ WHO Expert Committee on Food Additives [33]. Food additives are thus substances intentionally added to foodstuffs in small quantities generally aiming to improve their sensorial features and/or increase their time-span for consumption, and tocols, most particular tocopherols, are recognized as safe food additives by official food authorities [34-36]. Codex Alimentarius code numbers for $\mathrm{d}-\alpha$-tocopherol, dl- $\alpha$-tocopherol, and tocopherol concentrated mix (a mixture of several different types of vitamin E) are $307 \mathrm{a}$, $307 c$, and 307b [33]. The maximum levels of tocopherols in foods have been established by the Codex Alimentarius Commission and are summarized in Table 2.

As mentioned above, and again stressed, main tocols have vitamin $\mathrm{E}$ activity, although to different levels, in addition to other potential health benefits. In this respect, JECFA derived an acceptable daily intake (ADI) for vitamin $\mathrm{E}$ of $0.15-2 \mathrm{mg} / \mathrm{kg}$ body weight (bw)/day for $\mathrm{dl}-\alpha$-tocopherol [34] and Codex Alimentarius recommends the incorporation of tocopherols in some foods, namely, in vegetable oils to prevent rancidity, as the often necessary oil refining process causes a decrease in the concentration of this vitamin, as well as of other antioxidants that could be present in crude oil fractions. According to [38], for named vegetable oils, the authorized concentration of tocopherols (tocopherol, $\mathrm{d}-\alpha$, tocopherol concentrate, mixed and tocopherol, dl$\alpha$ ) is about $300 \mathrm{mg} / \mathrm{kg}$ (Table 2). The standard for olive oils and olive-pomace oils [39] recommend an addition level of tocopherols [d- $\alpha$-tocopherol (INS 307a), mixed tocopherol concentrate (INS 307b), and/or dl- $\alpha$-tocopherol (INS 307c)] to refined olive oil and other grades, stating that the concentration of $\alpha$-tocopherol in the final product shall not exceed $200 \mathrm{mg} / \mathrm{kg}$ [40].

From the European perspective, the use of food additives is regulated by specific laws in the European Union, supported by the evidence-based and expert opinions of the European Food Safety Authority (EFSA). These legal regulations consider the specificity of the food, in which the additive is incorporated, the maximum permitted quantity, the chemical structure, and the degree of purity [41] (Table 3).

EFSA derived a tolerable upper intake level (UL) for vitamin $\mathrm{E}$ of $300 \mathrm{mg} /$ day for adults [34]. The EFSA ANS panel has reevaluated the safety of tocopherols-rich extract of natural origin (E 306), synthetic $\alpha$-tocopherol (all-rac $\alpha$-tocopherol; dl- $\alpha$-tocopherol; E 307), synthetic $\gamma$-tocopherol (dl- $\gamma$ tocopherol; E 308), and synthetic $\delta$-tocopherol (E 309 ) on food additives, and nutrient sources added to food [34] and claimed that "tocopherols (E 306-E 309) are not of safety concern at the levels used in food".

Tocopherol occupies the category of antioxidants in the list of food additives. It is used in an extensive series of foodstuffs to abolish the oxidation of fatty acids and vitamins [42]. A considerable number of studies have focused on using tocopherols as additives in food [43-45]. Wagner and Elmadfa [45] have tested the effects of tocopherols and their mixtures on the oxidative stability of olive oil and linseed oil under heating. These authors registered an antioxidant activity at all levels of the addition of tocopherols that depended on the concentration level and the mixture of tocopherols. Incorporation of $\alpha$-tocopherol at up to $0.2 \%$ increased the oxidative stability of refined olive oil and decreased the formation of phytosterol oxidation products, as reported by Tabee et al. [44]. A comparative study on the impact of certain antioxidant compounds on the stability and prolongation of the mayonnaise's shelf life was carried 
TABLE 2: Example of general standard for food additives' provisions for tocopherols.

Food category

Aromatized alcoholic beverages (e.g., beer, wine, and spirituous cooler-type beverages, low alcoholic refreshers)

Batters (e.g., for breading or batters for fish or poultry)

Beverages whiteners

Breakfast cereals, including rolled oats

Butter oil, anhydrous milk fat, ghee

Dried fruit

Flavored fluid milk drinks

Vegetables oils and fats

Fish oil and other animal fats

Adapted from the update to the 42nd session of [37] http://www.fao.org/gsfaonline/groups/details.html?id=2.

TABle 3: Use of tocopherols as food additives in accordance with European legislation.

General data The additive is authorized to be used in the following category (ies) $\begin{gathered}\text { Legislation (details on European } \\ \text { Regulation/Directive) }\end{gathered}$

(i) Fats and oils essentially free from water (excluding anhydrous milk fat)/ individual restriction/exception: quantum satis, except virgin olive oils and olive oils

(i) No. 1129/2011, applicable as from $01 / 06 / 2013$

(ii) Infant formulae as defined by directive 2006/141/EC (13.1.1)

(ii) No. 1129/2011, applicable as from $01 / 06 / 2013$

Tocopherol-rich extract E 306

(iii) Follow-on formulae as defined by directive 2006/141/EC (13.1.2)/ Individual restriction/exception: $\mathrm{ML}=10 \mathrm{mg} / \mathrm{kg}$

(iii) No. 1129/2011, applicable as from $01 / 06 / 2013$

(iv) Processed cereal-based foods and baby foods for infants and young children as defined by directive 2006/125/EC (13.1.3)/individual restriction/exception: $\mathrm{ML}=100 \mathrm{mg} / \mathrm{kg}$; only fat-containing cerealbased foods including biscuits and rusks and baby foods

(v) Other foods for young children (13.1.4)/individual restriction/ exception: $\mathrm{ML}=100 \mathrm{mg} / \mathrm{kg}$

(iv) No. 1129/2011, applicable as from $01 / 06 / 2013$

(v) (EU) No. 1129/2011, applicable as from $01 / 06 / 2013$

(i) Fats and oils essentially free from water (excluding anhydrous milk fat) (2.1)/individual restriction/exception: quantum satis, except virgin oils (i) No. 1129/2011, applicable as from and olive oils; $\mathrm{ML}=200 \mathrm{mg} / \mathrm{kg}$, only refined olive oils, including olive 01/06/2013 pomace oil

(ii) Infant formulae as defined by directive 2006/141/EC (13.1.1)

Alpha-tocopherol E (iii) Follow-on formulae as defined by directive 2006/141/EC (13.1.2)/ 307 individual restriction/exception : $\mathrm{ML}: 10 \mathrm{mg} / \mathrm{kg}$

(ii) No. 1129/2011, applicable as from $01 / 06 / 2013$

(iii) No. 1129/2011, applicable as from $01 / 06 / 2013$

(iv) Processed cereal-based foods and baby foods for infants and young children as defined by directive 2006/125/EC (13.1.3)/individual restriction/exception: $\mathrm{ML}=100 \mathrm{mg} / \mathrm{kg}$, only fat-containing cerealbased foods including biscuits and rusks and baby foods

(v) Other foods for young children (13.1.4)/individual restriction/ exception: ML: $100 \mathrm{mg} / \mathrm{kg}$

(iv) No. 1129/2011, applicable as from $01 / 06 / 2013$

(v) No. 1129/2011, applicable as from $01 / 06 / 2013$

(i) Fats and oils essentially free from water (excluding anhydrous milk fat) (2.1)/individual restriction/exception : ML : quantum satis, except virgin oils and olive oils

(ii) Infant formulae as defined by directive 2006/141/EC (13.1.1)

(iii) Follow-on formulae as defined by directive 2006/141/EC (13.1.2)/ individual restriction/exception: $\mathrm{ML}=10 \mathrm{mg} / \mathrm{kg}$

Gamma-tocopherol E 308

(iv) Processed cereal-based foods and baby foods for infants and young children as defined by directive 2006/125/EC (13.1.3)/Individual restriction/exception: $\mathrm{ML}=100 \mathrm{mg} / \mathrm{kg}$, only fat-containing cerealbased foods including biscuits and rusks and baby foods

(v) Other foods for young children (13.1.4)/individual restriction/ exception: $\mathrm{ML}=100 \mathrm{mg} / \mathrm{kg}$

(i) No. 1129/2011, applicable as from $01 / 06 / 2013$

(ii) No. 1129/2011, applicable as from $01 / 06 / 2013$

(iii) Legislation: (EU) no. 1129/2011, applicable as from 01/06/2013

(iv) No. 1129/2011, applicable as from $01 / 06 / 2013$

(v) No. 1129/2011, applicable as from 01/06/2013 
TABLE 3: Continued.

\begin{tabular}{|c|c|c|}
\hline General data & The additive is authorized to be used in the following category (ies) & $\begin{array}{l}\text { Legislation (details on European } \\
\text { Regulation/Directive) }\end{array}$ \\
\hline \multirow{5}{*}{$\begin{array}{l}\text { Delta-tocopherol E } \\
309\end{array}$} & $\begin{array}{l}\text { (i) Fats and oils essentially free from water (excluding anhydrou } \\
(2.1) / \text { individual restriction/exception: } \mathrm{ML}=\text { quantum satis, } \\
\text { virgin oils and olive oils }\end{array}$ & $\begin{array}{l}\text { (i) No. } 1129 / 2011 \text {, applicable as from } \\
01 / 06 / 2013\end{array}$ \\
\hline & (ii) Infant formulae as defined by directive 2006/141/EC (13.1.1) & \multirow{4}{*}{$\begin{array}{l}\text { (ii) No. } 1129 / 2011 \text {, applicable as from } \\
01 / 06 / 2013 \\
\text { (iii) No. } 1129 / 2011 \text {, applicable as from } \\
01 / 06 / 2013 \\
\text { (iv) No. } 1129 / 2011 \text {, applicable as from } \\
01 / 06 / 2013 \\
\text { (v) No. 1129/2011, applicable as from } \\
01 / 06 / 2013 \text { ) }\end{array}$} \\
\hline & $\begin{array}{l}\text { (iii) Follow-on formulae as defined by directive 2006/141/EC (13.1.2)/ } \\
\text { individual restriction/exception: } \mathrm{ML}=10 \mathrm{mg} / \mathrm{kg}\end{array}$ & \\
\hline & $\begin{array}{l}\text { (iv) Processed cereal-based foods and baby foods for infants and young } \\
\text { children as defined by directive } 2006 / 125 / \mathrm{EC}(13.1 .3) / \text { individual } \\
\text { restriction/exception: } \mathrm{ML}=100 \mathrm{mg} / \mathrm{kg} \text {, only fat-containing cereal- } \\
\text { based foods including biscuits and rusks and baby foods }\end{array}$ & \\
\hline & $\begin{array}{l}\text { (v) Other foods for young children (13.1.4)/individual restriction/ } \\
\text { exception: } \mathrm{ML}=100 \mathrm{mg} / \mathrm{kg}\end{array}$ & \\
\hline
\end{tabular}

out by Alizadeh et al. [43]. This study used tocopherols, rosemary essential oil, and Ferulago angulata extract, showing the high potency of tocopherol in maintaining the stability of mayonnaise. $10 \%$ of the extract from the tocopherol solution was able to scavenge up to $99 \%$ of free radicals from DPPH (2, 2-diphenyl-1-picrylhydrazyl). Tocopherol was notable in controlling the primary oxidation steps (after four months of storage), showing a considerable capability to inhibit the formation of some secondary products, such as hexanal and heptanal [43]. The overall acceptability of the mayonnaise supplemented with tocopherol was good in terms of the sensory score, and the molecule seems to be compatible with mayonnaise's flavor. Based on this study, the authors recommended using tocopherols as an alternative to synthetic antioxidants in food [43].

\section{Final Remarks}

Tocols encompass tocopherols and tocotrienols, collectively known as vitamin $\mathrm{E}$, and are associated with lipids in animalbased (e.g., dairy) and vegetable-based (e.g., oils and nuts) food. Chemical reactions, which lead to the degradation of food constituents under processing and storage conditions, may cause the accumulation of compounds that compromise the sensorial and nutritional quality of foodstuffs. Notably, the oxidative deterioration of fat-rich food can be protected by tocols. Under food processing and storage conditions, tocols offer protection against oxidative deterioration of foodstuffs.

The consumption of natural and organic foods is becoming more and more fashionable and is gaining new markets in spite of ultra-processed foods. However, the vulnerability of certain foodstuffs, such as the oxidation of fats and oils, poses the problem of the addition of additives to avoid color changes, rancidity, and the appearance of undesirable tastes and odors. A scan of scientific research confirms the relevance of tocopherols in maintaining the sensory properties of foods in addition to their role as effective antioxidants. In fact, their physicochemical properties, low volatility, and good solubility in fats and oils give them the necessary resistance to processes using high temperatures. They have been incorporated into many formulations including baked goods, grains, dehydrated potatoes, fried nuts and noodles, meat and eggs, and tuna fillets. On the other side, while the tocopherols have been investigated extensively, little is known about the tocotrienols but some studies suggest that both the molecular and therapeutic targets of the tocotrienols are distinct from those of the tocopherols, and their role in cancer prevention and treatment, as well as in cardiovascular and neurological diseases, awaits further investigation.

\section{Data Availability}

The data (from literature review and databases) used to support the current work are included within the article.

\section{Conflicts of Interest}

The authors declare that there are no conflicts of interest related to the present work.

\section{Authors' Contributions}

AM Delgado and MFR Hassanien structured the manuscript; AM Delgado and M Issaoui wrote the manuscript with collaboration of S Al-Hamimi and MRF Hassanien; AM. Delgado, M Issaoui, and MFR Hassanien reviewed the manuscript with collaboration of M De Wit, A Durazzo, and KL Nyam.

\section{Acknowledgments}

The authors would like to thank Miss Ilhem Issaoui, currently a Ph.D. student in American literature at the Faculty of Arts and Humanities of Sfax, Sfax, Tunisia, for support in writing and for the proofreading of the current review.

\section{References}

[1] L. Mène-Saffrané and D. DellaPenna, "Biosynthesis, regulation and functions of tocochromanols in plants," 
Plant Physiology and Biochemistry, vol. 48, no. 5, pp. 301-309, 2010.

[2] European Food Information Council EUFIC, "Drivers of choice: what motivates consumer behaviour," 2016, https://www.eufic.org/en/healthy-living/article/drivers-ofchoice-what-motivates-consumer-behaviour.

[3] UN Environment, Global Environmental Outlook-GEO-6: Healthy Planet, Healthy People, Cambridge University Press, Cambridge, England, 2019.

[4] World Health Organization, WHO, Obesity and Overweight, WHO, Geneva, Switzerland, 2020, https://www.who.int/ news-room/fact-sheets/detail/obesity-and-overweight.

[5] FAO, Sustainable Healthy Diets-Guiding Principles, FAO, Rome, Italy, 2019.

[6] W. Willett, J. Rockström, B. Loken et al., "Food in the anthropocene: the EAT-lancet commission on healthy diets from sustainable food systems," The Lancet, vol. 393, no. 10170, pp. 447-492, 2019.

[7] M. Issaoui, A. M. Delgado, G. Caruso et al., "Phenols, flavors, and the mediterranean diet," Journal of AOAC International, vol. 103, no. 4, pp. 915-924, Article ID qsz018, 2020.

[8] L. F. Ruini, R. Ciati, C. A. Pratesi, M. Marino, L. Principato, and E. Vannuzzi, "Working toward healthy and sustainable diets: the "double pyramid model" developed by the barilla center for food and nutrition to raise awareness about the environmental and nutritional impact of foods," Frontiers in Nutrition, vol. 2, p. 9, 2015.

[9] M. D. Vaz Almeida, S. Parisi, and A. M. Delgado, "Food and nutrient features of the mediterranean diet," in Chemistry of the Mediterranean Diet, Springer, Cham, Switzerland, 2017.

[10] A. Di Vincenzo, C. Tana, H. El Hadi, C. Pagano, R. Vettor, and M. Rossato, "Antioxidant, anti-inflammatory, and metabolic properties of tocopherols and tocotrienols: clinical implications for vitamin E supplementation in diabetic kidney disease," International Journal of Molecular Sciences, vol. 20, no. 20 , p. 5101, 2019.

[11] A. Braud and Y. Boucher, "Intra-oral trigeminal-mediated sensations influencing taste perception: a systematic review," Journal of Oral Rehabilitation, vol. 47, no. 2, pp. 258-269, 2020.

[12] J. M. Eaton, N. K. Dess, and C. D. Chapman, "Sweet success, bitter defeat: a taste phenotype predicts social status in selectively bred rats," PLoS One, vol. 7, no. 10, Article ID e46606, 2012.

[13] V. Aggarwal, D. Kashyap, K. Sak et al., "Molecular mechanisms of action of tocotrienols in cancer: recent trends and advancements," International Journal of Molecular Sciences, vol. 20, no. 3, p. 656, 2019.

[14] F. Shahidi and A. De Camargo, "Tocopherols and tocotrienols in common and emerging dietary sources: occurrence, applications, and health benefits," International Journal of Molecular Sciences, vol. 17, no. 10, p. 1745, 2016.

[15] G. Bjelakovic, D. Nikolova, and C. Gluud, "Meta-regression analyses, meta-analyses, and trial sequential analyses of the effects of supplementation with beta-carotene, vitamin A, and vitamin E singly or in different combinations on all-cause mortality: do we have evidence for lack of harm?" PLoS One, vol. 8, no. 9, Article ID e74558, 2013.

[16] D. DellaPenna and B. J. Pogson, "Vitamin synthesis in plants: tocopherols and carotenoids," Annual Review of Plant Biology, vol. 57, no. 1, pp. 711-738, 2006.

[17] Q. Jiang, "Natural forms of vitamin E: metabolism, antioxidant, and anti-inflammatory activities and their role in disease prevention and therapy," Free Radical Biology and Medicine, vol. 72, pp. 76-90, 2014.

[18] J. K. Pandya, M. DeBonee, M. G. Corradini, M. E. Camire, D. J. McClements, and A. J. Kinchla, "Development of vitamin E-enriched functional foods: stability of tocotrienols in food systems," International Journal of Food Science \& Technology, vol. 54, no. 12, pp. 3196-3204, 2019.

[19] C. K. Sen, S. Khanna, and S. Roy, "Tocotrienols in health and disease: the other half of the natural vitamin E family," Molecular Aspects of Medicine, vol. 28, no. 5-6, pp. 692-728, 2007.

[20] European Food Safety Authority EFSA, "Scientific opinion on dietary reference values for vitamin $\mathrm{E}$ as $\alpha$-tocopherol (EFSA panel on dietetic products, nutrition and allergies)," EFSA Journal, vol. 13, no. 7, p. 4149, 2015.

[21] National Institutes of Health, NIH, Fact Sheet by the Office of Dietary Supplements (ODS), NIH, Bethesda, MD, USA, 2020, https://ods.od.nih.gov/factsheets/VitaminE-HealthProfessional/.

[22] M. Issaoui and A. M. Delgado, "Grading, labeling and standardization of edible oils," in Fruit Oils: Chemistry and Functionality, pp. 9-52, Springer International Publishing, New York, NY, USA, 2019.

[23] E. Kondratowicz-Pietruszka, L. Ostasz, and K. Tataruch, "The dynamics of oxidative changes in selected fats during the frying of French fries," Acta Scientiarum Polonorum Technologia Alimentaria, vol. 18, no. 3, pp. 293-303, 2019.

[24] Q. Li, J. Chen, Z. Huyan et al., "Application of Fourier transform infrared spectroscopy for the quality and safety analysis of fats and oils: a review," Critical Reviews in Food Science and Nutrition, vol. 59, no. 22, pp. 3597-3611, 2019.

[25] B. L. Sailo, K. Banik, G. Padmavathi, M. Javadi, D. Bordoloi, and A. B. Kunnumakkara, "Tocotrienols: the promising analogues of vitamin E for cancer therapeutics," Pharmacological Research, vol. 130, pp. 259-272, 2018.

[26] K. M. Ranard and J. W. Erdman, "Effects of dietary RRR $\alpha$-tocopherol vs. all-racemic $\alpha$-tocopherol on health outcomes," Nutrition Reviews, vol. 76, no. 3, pp. 141-153, 2018.

[27] L. Schmölz, M. Birringer, S. Lorkowski, and M. Wallert, "Complexity of vitamin E metabolism," World Journal of Biological Chemistry, vol. 7, no. 1, pp. 14-43, 2016.

[28] K. Jomova and M. Valko, "Health protective effects of carotenoids and their interactions with other biological antioxidants," European Journal of Medicinal Chemistry, vol. 70, pp. 102-110, 2013.

[29] J. Baudry, P. Pointereau, L. Seconda et al., "Improvement of diet sustainability with increased level of organic food in the diet: findings from the bionutrinet cohort," The American Journal of Clinical Nutrition, vol. 109, no. 4, pp. 1173-1188, 2019.

[30] C. M. Chaudhary, "Nutritional quality of organic food: shades of grey or shades of green?" Proceedings of the Nutrition Society, vol. 61, no. 1, pp. 19-24, 2002.

[31] X. Zhao, E. Chambers, Z. Matta, T. M. Loughin, and E. E. Carey, "Consumer sensory analysis of organically and conventionally grown vegetables," Journal of Food Science, vol. 72, no. 2, pp. S87-S91, 2007.

[32] O. Idris, O. Wintola, and A. Afolayan, "Comparison of the proximate composition, vitamins (ascorbic acid, $\alpha$-tocopherol and retinol), anti-nutrients (phytate and oxalate) and the GCMS analysis of the essential oil of the root and leaf of rumex crispus L," Plants, vol. 8, no. 3, p. 51, 2019. 
[33] World Health Organization WHO, Food Additives, WHO, Geneva, Switzerland, 2018, https://www.who.int/news-room/ fact-sheets/detail/food-additives.

[34] European Food Safety Authority, EFSA, "Scientific Opinion on the re-evaluation of tocopherol-rich extract (E 306), $\alpha$-tocopherol (E 307), $\gamma$-tocopherol (E 308) and $\delta$-tocopherol (E 309) as food additives (EFSA panel on food additives and nutrient sources added to food)," EFSA Journal, vol. 13, no. 9, p. $4247,2015$.

[35] Standard for Olive Oils and Olive Pomace Oils CODEX STAN 33-1981; Rev 2013.

[36] G. Tomassi and V. Silano, "An assessment of the safety of tocopherols as food additives," Food and Chemical Toxicology, vol. 24, no. 10-11, pp. 1051-1061, 1986.

[37] General Standard for Food Additives, CODEX STAN 1921995-Rev. 2019.

[38] M. Montagnani Marelli, M. Marzagalli, F. Fontana, M. Raimondi, R. M. Moretti, and P. Limonta, "Anticancer properties of tocotrienols: a review of cellular mechanisms and molecular targets," Journal of Cellular Physiology, vol. 234, no. 2, pp. 1147-1164, 2019.

[39] Standard for Named Vegetable Oils CXS 210-1999-2019.

[40] JECFA (Joint FAO/WHO Expert Committee on Food Additives), "Tocopherol Concentrate, mixed," 2006), http://www.fao.org/ag/agn/jecfa-additives/details.html; jsessionid=5AA5B3321733596253BD521F4B633EE8?id=451.

[41] M. M. Silva and F. C. Lidon, "An overview on applications and side effects of antioxidant food additives," Emirates Journal of Food and Agriculture, vol. 28, no. 12, pp. 823-832, 2016.

[42] R. Pandey and S. Upadhyay, Food Additive, Y. E. Samragy, Ed., InTech, London, UK, 2012.

[43] L. Alizadeh, K. Abdolmaleki, K. Nayebzadeh, and R. Shahin, "Effects of tocopherol, rosemary essential oil and ferulago angulata extract on oxidative stability of mayonnaise during its shelf life: a comparative study," Food Chemistry, vol. 285, pp. 46-52, 2019.

[44] E. Tabee, S. Azadmard-Damirchi, M. Jägerstad, and P. C. Dutta, "Effects of $\alpha$-tocopherol on oxidative stability and phytosterol oxidation during heating in some regular and high-oleic vegetable oils," Journal of the American Oil Chemists' Society, vol. 85, no. 9, pp. 857-867, 2008.

[45] K. H. Wagner and I. Elmadfa, "Effects of tocopherols and their mixtures on the oxidative stability of olive oil and linseed oil under heating," European Journal of Lipid Science and Technology, vol. 102, no. 10, 2000. 